\title{
In vivo biofunctional evaluation of hydrogels for disc regeneration
}

\author{
Sandra Reitmaier · Ludwika Kreja • Katharina Gruchenberg • Britta Kanter • \\ Joana Silva-Correia $\cdot$ Joaquim Miguel Oliveira $\cdot$ Rui Luís Reis $\cdot$ Valeria Perugini \\ Matteo Santin · Anita Ignatius $\cdot$ Hans-Joachim Wilke
}

Received: 23 August 2013/Revised: 31 August 2013/Accepted: 31 August 2013/Published online: 12 October 2013

(C) The Author(s) 2013. This article is published with open access at Springerlink.com

\begin{abstract}
Purpose Regenerative strategies aim to restore the original biofunctionality of the intervertebral disc. Different biomaterials are available, which might support disc regeneration. In the present study, the prospects of success of two hydrogels functionalized with anti-angiogenic peptides and seeded with bone marrow derived mononuclear cells (BMC), respectively, were investigated in an ovine nucleotomy model.

Methods In a one-step procedure iliac crest aspirates were harvested and, subsequently, separated BMC were seeded on hydrogels and implanted into the ovine disc. For the cell-seeded approach a hyaluronic acid-based hydrogel was used. The anti-angiogenic potential of newly developed VEGF-blockers was investigated on ionically crosslinked metacrylated gellan gum hydrogels. Untreated discs
\end{abstract}

S. Reitmaier $(\bowtie) \cdot$ L. Kreja $\cdot$ K. Gruchenberg $\cdot$ B. Kanter ·

A. Ignatius · H.-J. Wilke

Center of Musculoskeletal Research, Institute of Orthopaedic

Research and Biomechanics, University of Ulm,

Helmholtzstrasse 14, 89081 Ulm, Germany

e-mail: sandra.reitmaier@uni-ulm.de

J. Silva-Correia $\cdot$ J. M. Oliveira $\cdot$ R. L. Reis

3B's Research Group-Biomaterials, Biodegradables and

Biomimetics, University of Minho, Headquarters of the

European Institute of Excellence on Tissue Engineering and

Regenerative Medicine, AvePark, S. Cláudio de Barco, Taipas,

Guimarães, Portugal

J. Silva-Correia $\cdot$ J. M. Oliveira $\cdot$ R. L. Reis

ICVS/3B's-PT Government Associate Laboratory,

Braga/Guimarães, Portugal

V. Perugini - M. Santin

School of Pharmacy and Biomolecular Sciences,

University of Brighton, Brighton, UK served as nucleotomy controls. 24 adult merino sheep were used. After 6 weeks histological, after 12 weeks histological and biomechanical analyses were conducted.

Results Biomechanical tests revealed no differences between any of the implanted and nucleotomized discs. All implanted discs significantly degenerated compared to intact discs. In contrast, there was no marked difference between implanted and nucleotomized discs. In tendency, albeit not significant, degeneration score and disc height index deteriorated for all but not for the cell-seeded hydrogels from 6 to 12 weeks. Cell-seeded hydrogels slightly decelerated degeneration.

Conclusions None of the hydrogel configurations was able to regenerate biofunctionality of the intervertebral disc. This might presumably be caused by hydrogel extrusion. Great importance should be given to the development of annulus sealants, which effectively exploit the potential of (cell-seeded) hydrogels for biological disc regeneration and restoration of intervertebral disc functioning.

Keywords Intervertebral disc - Degeneration . Regeneration · One-step · Sheep · Large animal model $\cdot$ In vivo

\section{Introduction}

Intervertebral disc degeneration (IDD) is a highly relevant individual and socioeconomic burden, which is associated to various morphological and functional disturbances [1]. The gradual progression of the disease and the structural features, e.g., the degradation of proteoglycans with subsequent desiccation of the disc extracellular matrix, the ingrowth of blood vessels and the loss of intervertebral disc 
(IVD) height, can be addressed in close detail and predispose IDD for regenerative strategies [2].

Currently, different approaches are being pursued to regenerate the IVD. Direct injection of growth factors, viral vectors and cells, each alone or in combination, seek to stimulate proliferation and production of extracellular matrix [3]. Reasonable chances of success of these methods, however, are questionable [4, 5]. Low oxygen and $\mathrm{pH}$ within the avascular disc represent a hostile environment for cell metabolism [2, 6, 7]. Conversely, vascularization must not be promoted as it accelerates degeneration [8, 9]. Furthermore, aberrant mechanical stimuli may activate catabolic remodelling, cell death and tissue breakdown [10-13].

To reestablish a loading regime that enhances the anabolic response of resident and implanted cells and to trigger biological mechanisms of self-healing, biodegradable substitutes were designed according to the natural ideal of the IVD. As the restoration of disc height is assumed to be essential for nucleus replacements, sufficient quantities of hydrogels are intended to be injected into the IVD for an immediate restoration of disc mechanics. Biomaterial extrusion, however, is of major biomechanical concern [14-16]. Hyaluronic acid or polysaccharide-based hydrogels, such as gellan gum-based hydrogels, were proven to adequately support the growth and extracellular matrix deposition of cells and might therefore be suited as nucleus replacements [17-19]. To retain avascularity of cartilaginous tissues, functionalization of scaffolds with antiangiogenic peptides was suggested [20].

To gain deeper knowledge on future research directions, the purpose of this study was to investigate newly developed hydrogels as nucleus replacements for the biomechanical restoration and biological regeneration of the disc. Different modifications of hydrogels were examined in an ovine nucleotomy model. The effect of functionalization on the efficiency of hydrogels was evaluated using antiangiogenic peptides and bone marrow derived mononuclear cells.

\section{Materials and methods}

24 adult Merino sheep (2-4.5 years; 76-108 kg) were operated to compare four different hydrogel configurations with nucleotomy controls. Permission for the animal experiment was received from the regional commission of Tübingen (Reg. Nr. 1032).

Configuration 1 Hydrogels made of ionic crosslinked methacrylated Gellan Gum (iGG-MA; 3B's Research Group, University of Minho, Portugal) were used as nucleus replacement. iGG-MA is a microbial polysaccharide, which forms a colloidal gel in the presence of metallic ions.
Configuration 2 To investigate whether anti-angiogenic peptides reveal a positive effect in the prevention of IDD, iGG-MA was functionalized with non-cytotoxic polylysine-based VEGF-blockers (iGG-MA+PEP) that were shown to effectively inhibit endothelial cell proliferation [20] (School of Pharmacy and Biomolecular Sciences, University of Brighton, United Kingdom).

Configuration 3 Hydrogels made of dodecyl-amide of hyaluronic acid (DDAHA; Anika Therapeutics, Abano Therme, Italy) were tested without additives.

Configuration 4 For the cell-based approach, DDAHA was seeded with autologous bone marrow derived mononuclear cells (DDAHA+BMC). A one-step surgical procedure was performed combining the harvesting of bone marrow (BM) from the iliac crest, the isolation of $\mathrm{BMC}$ and the orthotopic implantation of DDAHA+BMC.

Configuration 5 Nucleotomy control with no treatment.

The detailed composition of the hydrogels was previously described [21].

Preparation of cell-seeded scaffolds

In 18 animals one of four operated IVD received a cellseeded hydrogel. BM was harvested from the iliac crest under sterile conditions at the beginning of surgery. Coagulation was prevented by 5,000 IU heparin/10 ml BM (Heparin-Natrium-5,000-ratiopharm, ratiopharm $\mathrm{GmbH}$, Ulm, Germany).

BMC ("buffy coat") were isolated by buoyant density separation. The cell-seeded hydrogels were prepared by adding $0.25 \mathrm{ml}$ of the cell suspension containing $4 \times 10^{6}$ $\mathrm{BMC} / \mathrm{ml} \mathrm{PBS}$ to $0.5 \mathrm{ml}$ of DDAHA, resulting in $1 \times 10^{6}$ BMC/DDAHA. Control samples (DDAHA) were mixed with $0.25 \mathrm{ml}$ PBS without cells. Both hydrogels were transferred in sterile $2 \mathrm{ml}$ syringes for intraoperative application. For the estimation of the number of mesenchymal stem cells (MSC) in BMC a colony forming unitsfibroblast (CFU-F) assay was performed as previously described [22].

Orthotopic implantation of hydrogels

All animals were operated in four levels from L1-L2 to L4-L5 or in case of 7 lumbar vertebrae $(n=8)$ from L2L3 to L5-L6. General anesthesia and the retroperitoneal multisegmental approach to the spine were performed as recently described in detail [23]. Each disc was stabbed with sterile microsurgery blades and a lateral nucleotomy was performed using 1.0 and $1.5 \mathrm{~mm}$ rongeurs with straight and flexed jaws, respectively. Approximately $0.20 \mathrm{~g}(0.17-0.23 \mathrm{~g})$ nucleus tissue was removed from each disc and treated in an alternating sequence with one of the five configurations (Fig. 1). The annulus defects were 


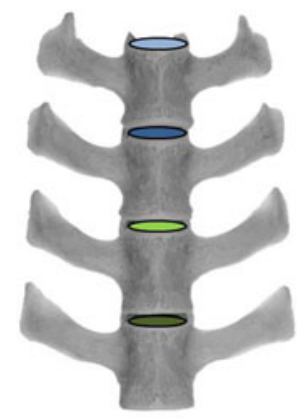

A

iGG-MA

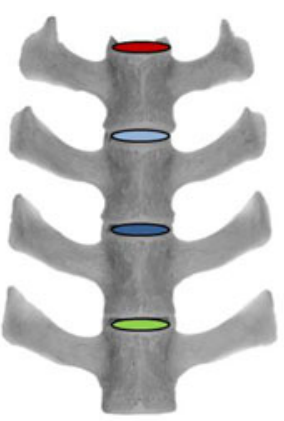

B

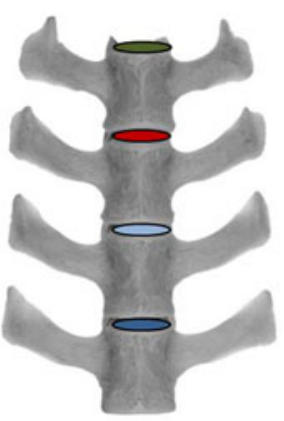

C

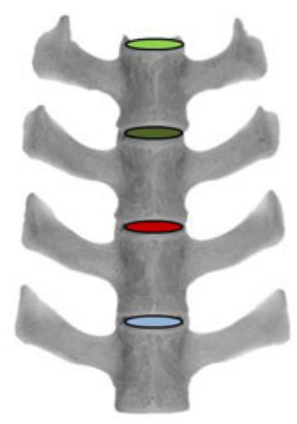

D

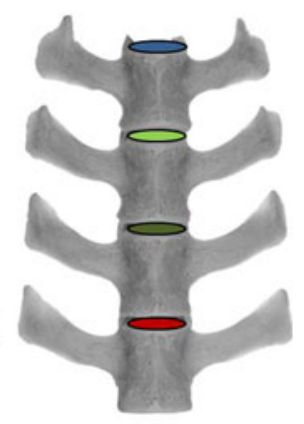

E

DDAHA+BMC

nucleotomy control

Fig. 1 Alternating implantation scheme for the two hydrogels (blue, green) without (light) and with peptides or cells (dark) and the nucleotomy controls (red)

closed with suture and 2-octyl-cyanoacrylate glue (DERMABOND ${ }^{\circledR}$, Ethicon Products, Norderstedt, Germany) and covered with a collagen sponge (Lyostypt ${ }^{\circledR}$, Aesculap AG, Tuttlingen, Germany).

Eight animals were sacrificed after 6 weeks for only histological and 16 sheep after 12 weeks for histological and biomechanical analyses. The 6-week group for biomechanics was omitted because after this time period annulus healing is not to be expected [24].

For biomechanical and histological comparison with intact discs, respectively, six native lumbar spines and six lumbar segments from independent comparable sheep were used.

Biomechanics

For the biomechanical analyses, the polysegmental specimens including all treated discs were embedded in polymethylmethacrylate (PMMA, Technovit 3040, Heraeus Kulzer, Werheim, Germany) and tested in a custom-made spine loading simulator $[25,26]$. The range of motion (RoM) and the neutral zone (NZ) were investigated for each segment separately at $\pm 7.5 \mathrm{Nm}$ pure moments in the three principal motion planes flexion + extension, lateral bending right + left, and axial rotation left + right using a motion tracking system (Vicon MX13, Vicon, Oxford, United Kingdom).

\section{Histology}

For qualitative and semi-quantitative histological evaluation each segment was embedded in PMMA for undecalcified histology after formalin fixation. Giemsa staining was performed using standard protocols. An established semi-quantitative degeneration score according
Table 1 Modified degeneration score according to Boos et al. [27]

\begin{tabular}{|c|c|c|}
\hline $\begin{array}{l}\text { Degeneration } \\
\text { parameter }\end{array}$ & Characteristic feature & $\begin{array}{l}\text { Score } \\
\text { (total 36) }\end{array}$ \\
\hline \multicolumn{3}{|l|}{ Intervertebral disc } \\
\hline \multirow[t]{6}{*}{ Cells } & No proliferation/ & 0 \\
\hline & Increased cell density/ & 1 \\
\hline & $\begin{array}{l}\text { Connection of two } \\
\text { chondrocytes/ }\end{array}$ & 2 \\
\hline & Small size clones/ & 3 \\
\hline & Moderate size clones/ & 4 \\
\hline & Huge size clones & 5 \\
\hline Granular changes & $\begin{array}{l}\text { None/rare/intermediate/ } \\
\text { abundantly }\end{array}$ & $0 / 1 / 2 / 3$ \\
\hline Neovascularization & Absent/present & $0 / 1$ \\
\hline Rim lesions & $\begin{array}{l}\text { None/rare/intermediate/ } \\
\text { abundantly }\end{array}$ & $0 / 1 / 2 / 3$ \\
\hline Concentric tears & $\begin{array}{l}\text { None/rare/intermediate/ } \\
\text { abundantly }\end{array}$ & $0 / 1 / 2 / 3$ \\
\hline Radial tears & $\begin{array}{l}\text { None/rare/intermediate/ } \\
\text { abundantly }\end{array}$ & $0 / 1 / 2 / 3$ \\
\hline Scar formation & Absent/present & $0 / 1$ \\
\hline Tissue defects & Absent/present & $0 / 1$ \\
\hline \multicolumn{3}{|l|}{ Endplate } \\
\hline Cells & $\begin{array}{l}\text { None/rare/intermediate/ } \\
\text { abundantly }\end{array}$ & $0 / 1 / 2 / 3$ \\
\hline $\begin{array}{l}\text { Structural } \\
\text { disorganization }\end{array}$ & $\begin{array}{l}\text { None/rare/intermediate/ } \\
\text { abundantly }\end{array}$ & $0 / 1 / 2 / 3$ \\
\hline Clefts & $\begin{array}{l}\text { None/rare/intermediate/ } \\
\text { abundantly }\end{array}$ & $0 / 1 / 2 / 3$ \\
\hline Microfracture & $\begin{array}{l}\text { None/rare/intermediate/ } \\
\text { abundantly }\end{array}$ & $0 / 1 / 2 / 3$ \\
\hline Neovascularization & Absent/present & $0 / 1$ \\
\hline New bone formation & Absent/present & $0 / 1$ \\
\hline Scar formation & Absent/present & $0 / 1$ \\
\hline Tissue defects & Absent/present & $0 / 1$ \\
\hline
\end{tabular}


Fig. 2 Total ranges of motion (RoM) and neutral zones (NZ) in flexion + extension (flex/ex), lateral bending right + left (lat bend) and axial rotation left + right $(a x$ rot $)$ for intact discs of separate sheep (green background) and for the five test configurations investigated in the current study. ${ }^{*} p<0.05$

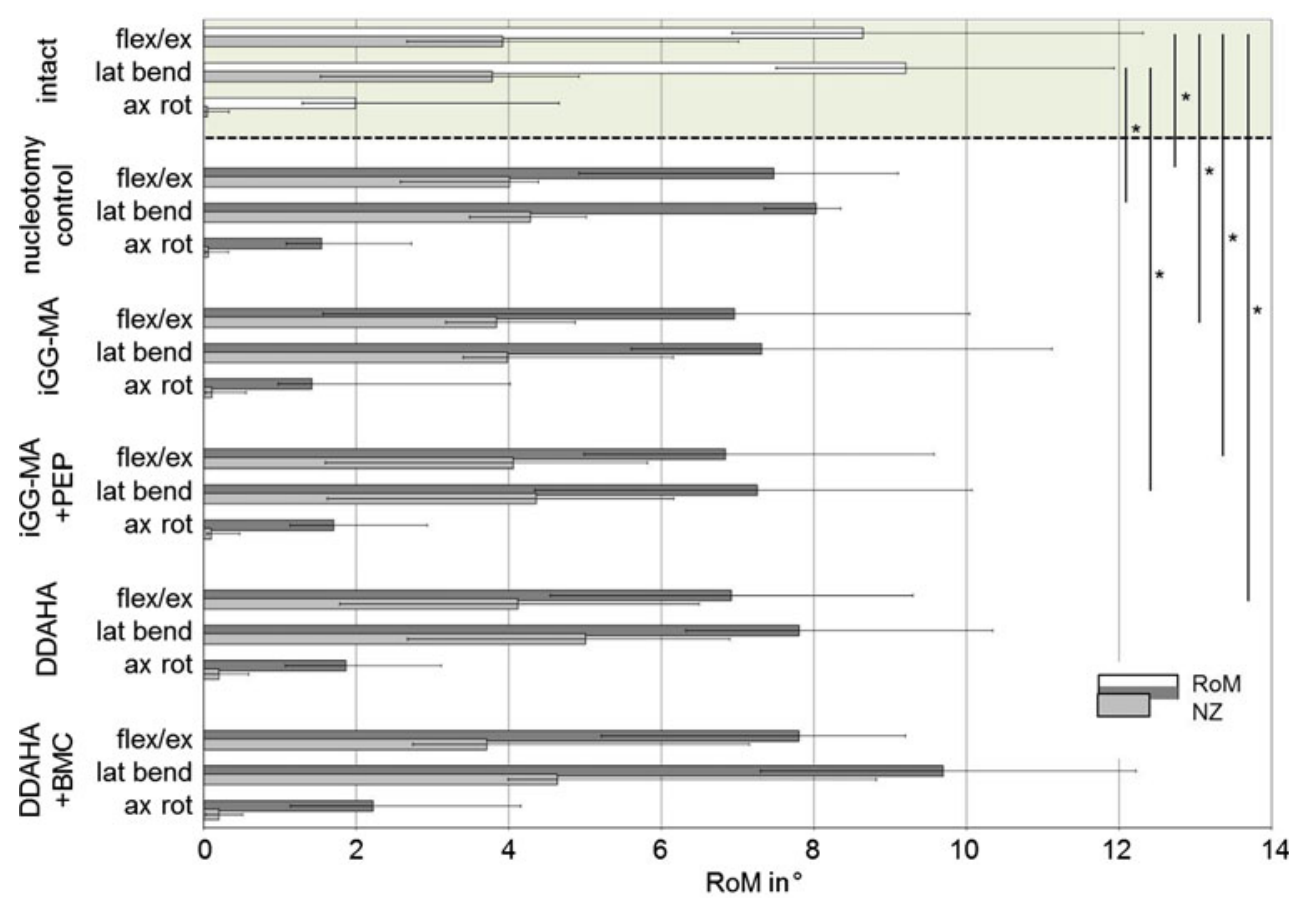

to Boos et al. [27] was used to determine the degree of degeneration (Table 1). The disc height index (DHI) was evaluated by dividing the mean value of the anterior, middle and posterior disc height from the histologic samples by the anterio-posterior diameter of the disc using ImageJ software [28]. Inflammation parameters, such as the presence of immune cells, regeneration of the tissue, blood vessel formation and remaining hydrogels were qualitatively evaluated under light microscopy (DMI6000B, Leica, Heerbrugg, Switzerland).

\section{Statistics}

For statistical analysis the unpaired, two-sample Wilcoxon signed rank test to a significance level of $p \leq 0.05$ was used. Statistics were performed using GnuR [29].

\section{Results}

Surgical interventions were well tolerated by the sheep. Intra- or post-operative complications did not occur.

\section{Cell isolation}

The yields of $\mathrm{BMC} / \mathrm{ml} \mathrm{BM}$ and the frequency of MSC evaluated by CFU-F assay varied considerably between the sheep. The mean $\pm \mathrm{SD}$ of $\mathrm{BMC} / \mathrm{ml} \mathrm{BM}$ was $1.11 \times 10^{6} \pm$ $0.95 \times 10^{6}$. The cloning efficiency of BMC population varied between $0.0008-0.039 \%$ CFU-F (mean $0.01 \pm 0.01 \%$ ). This resulted in the mean of $101 \pm 108 \mathrm{MSC} /$ hydrogel and varied between 8 and $390 \mathrm{MSC} / \mathrm{hydrogel}$. In average $0.20 \mathrm{ml}$ $(0.19-0.21 \mathrm{ml})$ of the cell-seeded hydrogels could be injected. The estimated number of BMC injected by DDAHA + BMC treatment therefore was about 270,000 .

\section{Biomechanics}

After 12 weeks in vivo, nucleotomy significantly decreased RoM compared to intact discs in flexion + extension $(p=0.02)$ and lateral bending ( $p=0.04$; Fig. 2$)$, but not in axial rotation. Significant decreased RoM was also found for iGG-MA + PEP in flexion + extension $(p=0.03)$ and lateral bending $(p=0.02)$. RoM for iGG-MA and DDAHA was significantly lower only in flexion + extension ( $p=0.04$ and 0.01 , respectively). DDAHA + BMC did not show significant differences at all. Compared to nucleotomy controls none of the hydrogel implanted discs revealed significant differences.

\section{Histology}

Histological sections showed marked differences between the surgically affected and intact discs 12 weeks after surgery. The structural integrity was obviously impaired in operated discs (Fig. 3). Tissue defects within the nucleus were similar in size in nucleotomy controls and hydrogel implanted discs. Hydrogels could not unambiguously be identified within the histological sections. Huge size cell clones were located in immediate vicinity of tissue defects inside the remaining nucleus pulposus tissue. Inflammation could not be found in any of the investigated samples. 

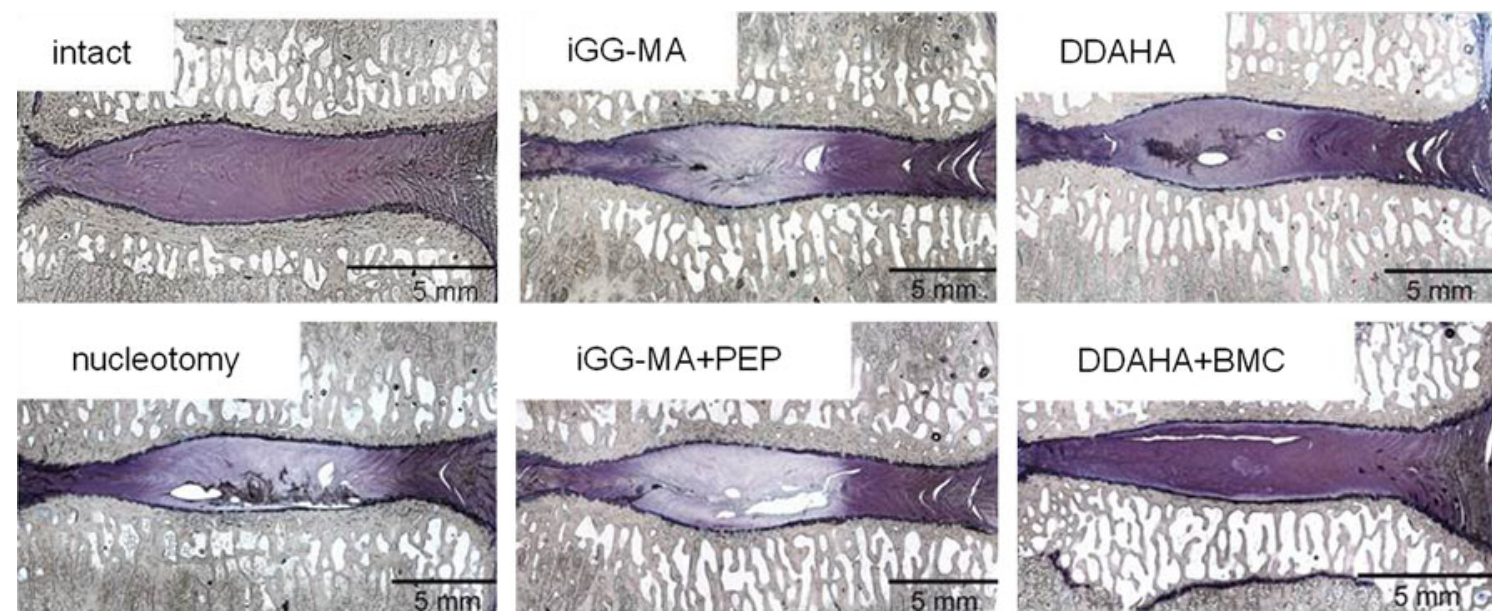

Fig. 3 Representative mid-sagittal histological sections of operated discs 12 weeks after surgery in comparison to an intact disc

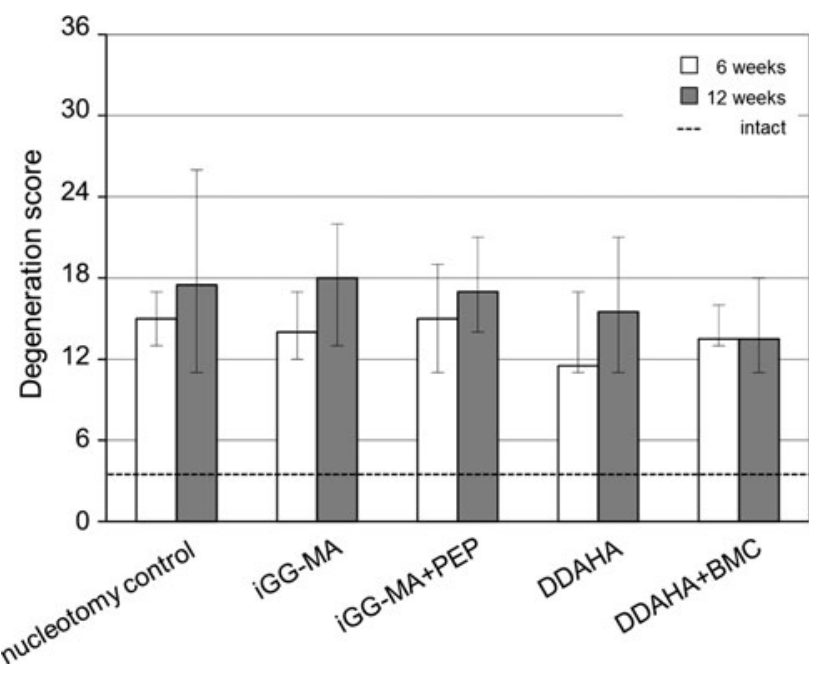

Fig. 4 Degeneration scores of intact discs (dashed line) were significantly less than of nucleotomy controls and hydrogel implanted discs $(p=0.003-0.005)$. There was no difference between nucleotomy controls and the four different material configurations both after 6 (white) and 12 weeks (grey)

Marked neovascularisation did not occur in any of the operated discs and, therefore, differences between the hydrogel implanted discs and the nucleotomy controls were not found. No differences in cellularity were seen. There was no visible formation of spondylophytes or bony endplate changes up to 12 weeks.

Intact discs revealed with a median degeneration score of 3.5 only negligible degenerative changes within the disc (Fig. 4). The degeneration score of all implanted and nucleotomized discs significantly differed from intact discs $(p=0.003-0.005)$. In contrast, there was no marked difference between the implanted discs and nucleotomy controls, neither after 6 nor 12 weeks. Comparing the results after 6 to results after 12 weeks, there was an obvious

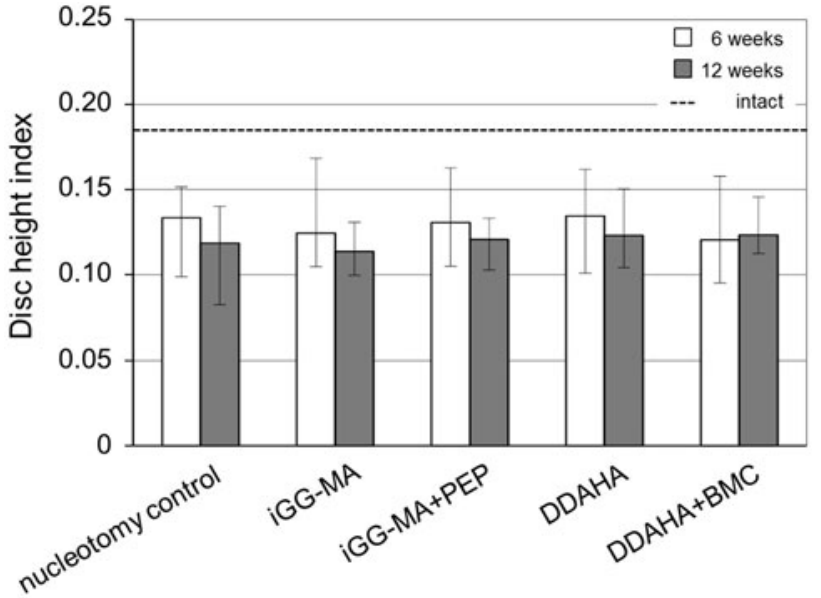

Fig. 5 Disc height indices of intact discs (dashed line) significantly differed from nucleotomy controls and hydrogel implanted discs $(p=0.003-0.013)$. No difference between nucleotomy controls and the different material configurations was found both 6 (white) and 12 weeks (grey) post-operatively

(although not significant) increase in the degeneration scores of nucleotomy controls $(17 \%)$ and all acellular test configurations (13-35\%). In DDAHA + BMC degeneration scores were kept almost constant.

DHI of intact discs were with $0.19(0.16-0.25)$ significantly higher than all operated discs at both time intervals (Fig. 5). After 6 weeks DHI of nucleotomy controls fell by $28 \%$ compared to intact discs. DHI of hydrogel implanted discs decreased in a similar range (iGG-MA: $-33 \%$, iGGMApep: $-30 \%$, DDAHA: $-27 \%$; DDAHA + BMC $-35 \%$ ). From 6 to 12 weeks post-operatively there was a progressive decrease in DHI for acellular hydrogels (iGGMA: $-9 \%$, iGG-MApep: $-8 \%$, DDAHA: $-9 \%$ ). DHI in DDAHA + BMC, however, seemed to be preserved $(+2 \%)$ even if this effect was not significant. Nucleotomy controls lost $11 \%$ of DHI between 6 and 12 weeks. 


\section{Discussion}

In this study using an ovine nucleotomy model, different configurations of newly developed hydrogels for nucleus replacements were investigated for their ability to restore RoM and disc height and to slow down IDD.

Results consistently showed that none of the tested hydrogel configurations proved to be superior to nucleotomy controls. The treatment with hydrogels was not able to restore disc height. However, against expectation, the operated discs showed a smaller ROM than intact discs. Histology of hydrogel implanted discs (acellular and cellular) showed more signs of degeneration as intact discs. There was a slight tendency that using BMC may eventually slow down IDD between 6 and 12 weeks of implantation.

The higher RoM of intact compared to nucleotomized discs found in this in vivo study is in contrast to in vitro data in literature, where RoM significantly increased after nucleotomy both for human [30] and for calf specimen [14, 31]. The same tendency was also found for ovine specimen in preliminary in vitro investigations for the current study (unpublished data). The discrepancy may be explained by general differences between in vitro conditions without healing, and the in vivo situation where collagenous bridges at the outer annulus were described 12 weeks after injury [32]. This initial bridging and the formation of scar tissue as well as the sealant method might be the reasons for the increased stiffness observed in this in vivo study.

The evaluation of the disc height index clearly proved that up to 12 weeks restoration of disc height could not be achieved using different hydrogel configurations as nucleus replacements after nucleotomy. This finding strongly indicates that relevant amounts of hydrogels were probably pressed out of the disc. This challenging problem of implant extrusion may also explain the similar disappointing degeneration scores both for the nucleotomy controls as well as for the hydrogel implanted discs.

Partial removal of nucleus was required for implantation of hydrogels as pure injection of a relevant amount of substitute materials into the healthy ovine disc is impossible because no cavity is available and intradiscal pressure in vivo is high [23]. Opening the annulus, however, inevitably causes the problem of extrusion. Sealants that reliably keep nucleus replacements inside the disc are urgently needed, but still not available. In previous in vitro studies, we have shown that the best of tested sealant options was cyanoacrylate glue combined with surgical suture [15]. Under axial compression, however, this sealant still allowed for gaping of the inner annulus defect with subsequent dislocation of implanted hydrogels and loss of intradiscal pressure in ovine motion segments [21]. To enhance the sealant efficiency in the current study, the closed defect was additionally covered with a collagen sponge. Artificial closure devices, proven to be effective to restore disc mechanics in vitro, unfortunately contradict to the main objective of disc regeneration and therefore were not used in the current study [33, 34].

Disc regeneration using hydrogels could not be achieved with this ovine nucleotomy model. This is in contrast to other animal experiments with rodents or pigs $[35,36]$. These different findings may be explained by the persistence of notochordal progenitor cells within the discs of these animals. Because in humans and likewise in sheep this cell type disappears, conclusions from the above mentioned species should be transferred to humans with caution $[37,38]$. Similar biology as well as similar anatomy and biomechanics suggest the sheep to be a more relevant model for humans [39-42].

The potential positive effect of BMC as additive in hydrogels for disc regeneration should be interpreted carefully. Only about $25 \mathrm{MSC} / \mathrm{disc}$ (range 2-70) provided in approximately $270,000 \mathrm{BMC}$ have been implanted. The optimal number of bone marrow derived MSC to be implanted into the degenerated disc to achieve a stimulating effect was found to be $10^{6}$ in dogs [43]. However, MSC yields in this order of magnitude are impossible to achieve without in vitro expansion. Low cell density applied is assumed to be the reason for limited observed effects. In vitro expansion of BMC prior to surgery might have reinforced the trends. The nevertheless promising perspectives of cell-based approaches for disc regeneration are in accordance to literature $[44,45]$. The right cell source, however, is still not finally clarified [46]. The BMC population used in the current study is a broad mixture of cell lineages in different differentiation stages containing multipotent mesenchymal and hemopoietic stem cells. Beneficial effects might be mediated by differentiation of MSC into IVD cells. Furthermore, BMC may act as trophic factor pools. Paracrine effects may cause BMC to secrete growth factors, cytokines and chemokines capable of stimulating the regeneration of injured tissue [47-49].

In case that the slight trend found in this study can be supported with future research, the perspective of applying non-cultivated BMC for disc regeneration in humans might be promising. Using the patients' own and unmodified cells might be an interesting solution which would probably lead to higher compliance of this new potential therapeutic option [50-52].

Injected cells were not labelled in the current study. As with the hydrogels, the fate of BMC after injection is, therefore, not known. This limitation is owed to the onestep surgical procedure using BMC without in vitro cultivation.

The durations of the animal study with 6 and 12 weeks may eventually have been too short to represent the 
regenerative capacity of the different hydrogel configurations. Longer test durations are therefore recommended when investigating biological strategies.

\section{Conclusion}

The results of present study indicate that because of presumed hydrogel extrusion, none of the investigated hydrogels was able to slow down IDD compared to nucleotomized discs. Therefore, the development of effective annulus sealants is crucial for successful nucleus replacement using hydrogels. Additional studies are recommended to substantiate the effects of non-cultivated cells for disc regeneration.

Acknowledgments This work was supported by the EU-project Disc Regeneration (NMP3-LA-2008-213904). Technical assistance of Iris Baum and the whole animal surgery team of the Institute of Orthopaedic Research and Biomechanics, Ulm, are gratefully acknowledged. DDAHA hydrogels were kindly provided by Cristina Longinotti (DDAHA, Anika Therapeutics, Abano Therme, Italy).

\section{Conflict of interest None.}

Open Access This article is distributed under the terms of the Creative Commons Attribution License which permits any use, distribution, and reproduction in any medium, provided the original author(s) and the source are credited.

\section{References}

1. Adams MA, Roughley PJ (2006) What is intervertebral disc degeneration, and what causes it? Spine 31(18):2151-2161

2. Roberts S, Evans H, Trivedi J, Menage J (2006) Histology and pathology of the human intervertebral disc. J Bone Jt Surg Am 88(Suppl 2):10-14

3. Paesold G, Nerlich AG, Boos N (2007) Biological treatment strategies for disc degeneration: potentials and shortcomings. Euro Spine J Off Publ Eur Spine Soc Eur Spinal Deform Soc Eur Sect Cerv Spine Res Soc 16(4):447-468

4. Kandel R, Roberts S, Urban JP (2008) Tissue engineering and the intervertebral disc: the challenges. Euro Spine J Off Publ Eur Spine Soc Eur Spinal Deform Soc Eur Sect Cerv Spine Res Soc 17(Suppl 4):480-491

5. Chan SC, Gantenbein-Ritter B (2012) Intervertebral disc regeneration or repair with biomaterials and stem cell therapy-feasible or fiction? Swiss medical weekly 142: w13598

6. Urban JP, Smith S, Fairbank JC (2004) Nutrition of the intervertebral disc. Spine 29(23):2700-2709

7. Raj PP (2008) Intervertebral disc: anatomy-physiology-pathophysiology-treatment. Pain Pract Off J World Inst Pain 8(1): $18-44$

8. Johnson WE, Evans H, Menage J, Eisenstein SM, El Haj A, Roberts S (2001) Immunohistochemical detection of Schwann cells in innervated and vascularized human intervertebral discs. Spine 26(23):2550-2557

9. Kauppila LI (1995) Ingrowth of blood vessels in disc degeneration. Angiographic and histological studies of cadaveric spines. J Bone Jt Surg Am 77(1):26-31
10. Ishihara H, McNally DS, Urban JP, Hall AC (1996) Effects of hydrostatic pressure on matrix synthesis in different regions of the intervertebral disk. J Appl Physiol 80(3):839-846

11. Neidlinger-Wilke C, Wurtz K, Urban JP, Borm W, Arand M, Ignatius A, Wilke HJ, Claes LE (2006) Regulation of gene expression in intervertebral disc cells by low and high hydrostatic pressure. Euro Spine J Off Publ Eur Spine Soc Eur Spinal Deform Soc Eur Sect Cerv Spine Res Soc 15(Suppl 3):S372-S378

12. Fernando HN, Czamanski J, Yuan TY, Gu W, Salahadin A, Huang CY (2011) Mechanical loading affects the energy metabolism of intervertebral disc cells. J Orthop Res Off Publ Orthop Res Soc 29(11):1634-1641

13. Chan SC, Ferguson SJ, Gantenbein-Ritter B (2011) The effects of dynamic loading on the intervertebral disc. Eur Spine $\mathrm{J}$ 20(11):1796-1812

14. Wilke HJ, Heuer F, Neidlinger-Wilke C, Claes L (2006) Is a collagen scaffold for a tissue engineered nucleus replacement capable of restoring disc height and stability in an animal model? Eur Spine J 15(Suppl 3):S433-S438

15. Heuer F, Ulrich S, Claes L, Wilke HJ (2008) Biomechanical evaluation of conventional anulus fibrosus closure methods required for nucleus replacement. Laboratory investigation. J Neurosurg Spine 9(3):307-313

16. Vadala G, Sowa G, Hubert M, Gilbertson LG, Denaro V, Kang JD (2012) Mesenchymal stem cells injection in degenerated intervertebral disc: cell leakage may induce osteophyte formation. J Tissue Eng Regen Med 6(5):348-355

17. Revell PA, Damien E, Di Silvio L, Gurav N, Longinotti C, Ambrosio L (2007) Tissue engineered intervertebral disc repair in the pig using injectable polymers. J Mater Sci Mater Med 18(2):303-308

18. Silva-Correia J, Miranda-Goncalves V, Salgado A, Sousa N, Oliveira JM, Reis RM, Reis RL (2012) Angiogenic potential of gellan gum-based hydrogels for application in nucleus pulposus regeneration: In vivo study. Tissue Eng. Part A

19. Silva-Correia J, Oliveira JM, Caridade SG, Oliveira JT, Sousa RA, Mano JF, Reis RL (2011) Gellan gum-based hydrogels for intervertebral disc tissue-engineering applications. J Tissue Eng Regen Med 5(6):e97-e107

20. Meikle ST, Perugini V, Guildford AL, Santin M (2011) Synthesis, characterisation and in vitro anti-angiogenic potential of dendron VEGF blockers. Macromol Biosci 11(12):1761-1765

21. Reitmaier S, Wolfram U, Ignatius A, Wilke HJ, Gloria A, Martinez JMM, Silva-Correia J, Oliveira JM, Reis RL,Schmidt H (2012) Hydrogels for nucleus replacement-facing the biomechanical challenge. J Mech Behav Biomed Mater

22. McCarty RC, Gronthos S, Zannettino AC, Foster BK, Xian CJ (2009) Characterisation and developmental potential of ovine bone marrow derived mesenchymal stem cells. J Cell Physiol 219:324-333

23. Reitmaier S, Schmidt H, Ihler R, Kocak T, Graf N, Ignatius A,Wilke H-J (in press) Preliminary Investigations on Intradiscal Pressures During Daily Activities: An In Vivo Study Using The Merino Sheep. PloS one

24. Ahlgren BD, Lui W, Herkowitz HN, Panjabi MM,Guiboux JP (2000) Effect of anular repair on the healing strength of the intervertebral disc: a sheep model. Spine (Phila Pa 1976) 25(17): 2165-2170

25. Wilke HJ, Claes L, Schmitt H, Wolf S (1994) A universal spine tester for in vitro experiments with muscle force simulation. Euro Spine J Off Publ Eur Spine Soc Eur Spinal Deform Soc Eur Sect Cerv Spine Res Soc 3(2):91-97

26. Wilke HJ, Wenger K, Claes L (1998) Testing criteria for spinal implants: recommendations for the standardization of in vitro stability testing of spinal implants. Eur Spine J 7(2):148-154 
27. Boos N, Weissbach S, Rohrbach H, Weiler C, Spratt KF, Nerlich AG (2002) Classification of age-related changes in lumbar intervertebral discs: 2002 Volvo Award in basic science. Spine 27(23):2631-2644

28. $1.45 \mathrm{~s}$ I (Wayne Rasband, National Institute of Health). Available at http://imagej.nih.gov/ij

29. Team RDC (2011) R: A language and environment for statistical computing. R Foundation for Statistical Computing, Vienna, Austria. ISBN 3-900051-07-0. Available at http://www.R-project. org/

30. Wilke HJ, Kavanagh S, Neller S, Haid C, Claes LE (2001) Effect of a prosthetic disc nucleus on the mobility and disc height of the L4-5 intervertebral disc postnucleotomy. J Neurosurg $95(2$ Suppl):208-214

31. Hegewald AA, Knecht S, Baumgartner D, Gerber H, Endres M, Kaps C, Stussi E,Thome C (2009) Biomechanical testing of a polymer-based biomaterial for the restoration of spinal stability after nucleotomy. J Orthop Surg Res 4: 25

32. Melrose J, Roberts S, Smith S, Menage J, Ghosh P (2002) Increased nerve and blood vessel ingrowth associated with proteoglycan depletion in an ovine anular lesion model of experimental disc degeneration. Spine 27(12):1278-1285

33. Arthur A, Cannella M, Keane M, Singhatat W, Vresilovic E, Marcolongo M (2010) Fill of the nucleus cavity affects mechanical stability in compression, bending, and torsion of a spine segment, which has undergone nucleus replacement. Spine 35(11):1128-1135

34. Wilke HJ, Ressel L, Heuer F, Graf N, Rath S (2013) Can prevention of a reherniation be investigated? Establishment of a herniation model and experiments with an anular closure device. Spine 38(10):E587-E593

35. Buser Z, Kuelling F, Liu J, Liebenberg E, Thorne KJ, Coughlin D, Lotz JC (2011) Biological and biomechanical effects of fibrin injection into porcine intervertebral discs. Spine 36(18):E1201E1209

36. Huang B, Zhuang Y, Li CQ, Liu LT, Zhou Y (2011) Regeneration of the intervertebral disc with nucleus pulposus cell-seeded collagen II/hyaluronan/chondroitin-6-sulfate tri-copolymer constructs in a rabbit disc degeneration model. Spine 36(26): 2252-2259

37. Hunter CJ, Matyas JR, Duncan NA (2004) Cytomorphology of notochordal and chondrocytic cells from the nucleus pulposus: a species comparison. J Anat 205(5):357-362

38. Alini M, Eisenstein SM, Ito K, Little C, Kettler AA, Masuda K, Melrose J, Ralphs J, Stokes I, Wilke HJ (2008) Are animal models useful for studying human disc disorders/degeneration? Eur Spine J 17(1):2-19
39. Reid JE, Meakin JR, Robins SP, Skakle JM,Hukins DW (2002) Sheep lumbar intervertebral discs as models for human discs. Clin Biomech (Bristol, Avon) 17(4): 312-314

40. Beckstein JC, Sen S, Schaer TP, Vresilovic EJ, Elliott DM (2008) Comparison of animal discs used in disc research to human lumbar disc: axial compression mechanics and glycosaminoglycan content. Spine 33(6):E166-E173

41. Wilke HJ, Kettler A, Claes LE (1997) Are sheep spines a valid biomechanical model for human spines? Spine 22(20):2365-2374

42. Wilke HJ, Kettler A, Wenger KH, Claes LE (1997) Anatomy of the sheep spine and its comparison to the human spine. Anat Rec 247(4):542-555

43. Serigano K, Sakai D, Hiyama A, Tamura F, Tanaka M, Mochida J (2010) Effect of cell number on mesenchymal stem cell transplantation in a canine disc degeneration model. J Orthop Res Off Publ Orthop Res Soc 28(10):1267-1275

44. Leung VY, Chan D, Cheung KM (2006) Regeneration of intervertebral disc by mesenchymal stem cells: potentials, limitations, and future direction. Euro Spine J Off Publ Eur Spine Soc Eur Spinal Deform Soc Eur Sect Cerv Spine Res Soc 15(Suppl 3):S406-S413

45. Sheikh H, Zakharian K, De La Torre RP, Facek C, Vasquez A, Chaudhry GR, Svinarich D, Perez-Cruet MJ (2009) In vivo intervertebral disc regeneration using stem cell-derived chondroprogenitors. J Neurosurg Spine 10(3):265-272

46. Drazin D, Rosner J, Avalos P, Acosta F (2012) Stem cell therapy for degenerative disc disease. Adv Orthop 2012: 961052

47. Ren G, Chen X, Dong F, Li W, Ren X, Zhang Y, Shi Y (2012) Concise review: mesenchymal stem cells and translational medicine: emerging issues. Stem Cell Transl Med 1:51-58

48. Wang S, Qu X,Zhao RC (2012) Clinical applications of mesenchymal stem cells. J Hematol Oncol 5: 19. Available at http:// www.jhoonline.org/content/15/11/19

49. Wen Z, Zheng S, Zhou C, Wang J, Wang T (2011) Repair mechanisms of bone marrow mesenchymal cells in myocardial infraction. J Cell Mol Med 15:1032-1043

50. Bernardo ME, Fibbe WE (2012) Safety and efficacy of mesenchymal stromal cell therapy in autoimmune disorders. Ann NY Acad Sci 1266:107-117

51. Lepperdinger G, Brunauer R, Jamnig A, Laschober G, Kassem M (2008) Controversial issue: is it safe to employ mesenchymal stem cells in cell-based therapies? Exp Gerontol 43(11): 1018-1023

52. So K, Takemoto M, Fujibayashi S, Neo M, Kyomoto M, Hayami T, Hyon SH, Nakamura T (2007) Antidegenerative effects of partial disc replacement in an animal surgery model. Spine 32(15):1586-1591 